\title{
CORROSIVIDADE DOS SOLOS DA REGIÃO CARBONÍFERA DO RIO GRANDE DO SUL SOBRE TUBULAÇÕES METÁLICAS ENTERRADAS
}

\section{CAMILE ERTHAL $^{1}$, KAUANA SERPA WERNER $^{2}$, LUISA BATAGLIN AVILA ${ }^{3}$, MARIA REGINA DE OLIVEIRA CASARTELLI ${ }^{4}$, SABRINA NEVES DA SILVA ${ }^{5}$, LUCIANA MACHADO RODRIGUES ${ }^{6}$}

\author{
1,2,3,6 Engenharia Química, UNIPAMPA - Campus Bagé, Bagé - RS. \\ ${ }^{4}$ Licenciatura em Química, UNIPAMPA - Campus Bagé, Bagé - RS. \\ ${ }^{5}$ Engenharia de Energia, UNIPAMPA - Campus Bagé, Bagé - RS. \\ E-mail para contato: erthalcamile@gmail.com
}

\begin{abstract}
RESUMO - A corrosividade dos solos é um importante fator a ser considerado devido à grande quantidade de estruturas metálicas neles enterradas. A degradação de tubulações pode ocasionar vazamentos, com risco de morte e dano ambiental. Neste trabalho foi avaliada a corrosividade de solos da região carbonífera do Rio Grande do Sul, localizada no sul do estado, sobre tubulações enterradas. Os solos foram caracterizados por microscopia, condutividade elétrica e pH. As amostras de aço foram preparadas por lixamento e expostas aos solos estudados, durante 10 meses. A morfologia da corrosão do aço foi monitorada por microscopia e análise gravimétrica. Os resultados indicam um processo corrosivo acelerado nos solos de maiores condutividade elétrica e acidez, Candiota e Pinheiro Machado, localizados mais próximos das jazidas de carvão mineral. Concluiu-se que para o período de exposição analisado, a corrosividade dos solos da região carbonífera do RS, foi suficiente para iniciar um processo corrosivo em aço enterrado.
\end{abstract}

\section{INTRODUÇÃO}

Corrosão é um fenômeno natural, definida como a deterioração de um material, usualmente um metal, resultante de reações químicas ou eletroquímicas com seu ambiente (NACE/ASTM, 2012). O solo é um complexo meio corrosivo e a velocidade da corrosão é influenciada pela sua natureza, através dos principais parâmetros, $\mathrm{pH}$, presença de água, sais solúveis, gases, potencial redox, resistividade elétrica, e acidez (GENTIL, 2011; PANOSSIAN, 1993).

O estudo do solo como meio corrosivo tem grande importância devido ao elevado número de estruturas enterradas, como oleodutos, gasodutos, e tanques para armazenamento de combustíveis. A corrosão nestas estruturas pode causar perfurações que levam a vazamentos, e como consequiência ocorre contaminação do solo ou lençóis freáticos (GENTIL, 2011). 
Um dos parâmetros fundamentais relativos à agressividade do solo é a sua resistividade elétrica. A taxa de corrosão de uma estrutura metálica enterrada está diretamente relacionada à resistividade, uma vez que solos de menor resistividade proporcionam maiores taxas de corrosão. Por sua vez, a resistividade depende das características do solo, tais como permeabilidade, umidade, sais dissolvidos e valor de $\mathrm{pH}$ (LOUREIRO, 2005).

A corrosividade de solos pode também ser influenciada pela chuva, ocasionando o aumento da sua umidade e diminuição da resistividade elétrica, bem como a formação de chuva ácida. Nesse último caso, a chuva ácida está presente em áreas nas quais ocorre a queima do carvão com a liberação dos compostos de enxofre. Estes compostos em contato com a umidade formam a chuva ácida, tornando os solos destes locais ácidos, e acelerando o processo corrosivo de estruturas metálicas enterradas (GENTIL, 2011).

A Usina Termelétrica Presidente Médici - UTPM - Candiota II, do tipo térmica à vapor, está localizada no município de Candiota, distante $400 \mathrm{~km}$ de Porto Alegre. A história do complexo termelétrico de Candiota inicia em $1950 \mathrm{com}$ as primeiras pesquisas sobre o aproveitamento do carvão mineral para geração de energia elétrica. A construção desse empreendimento significou a retomada da utilização do carvão na produção de energia elétrica para atendimento do mercado brasileiro, duplicando o consumo deste combustível no estado do Rio Grande do Sul (CGTEE, 2017).

A Usina utiliza para a produção de energia elétrica o carvão mineral pulverizado. Os impactos ambientais mais relevantes da queima deste combustível se dão principalmente pelas emissões aéreas liberadas durante o período de operação da usina, as quais se depositam em solos, águas e estruturas expostas à céu aberto (CGTEE, 2017).

O presente trabalho teve como objetivo avaliar a corrosividade de solos de seis cidades diferentes da região carbonífera do Rio Grande do Sul, caracterizando os mesmos e o ataque gerado a tubulações metálicas enterradas.

\section{MATERIAIS E MÉTODOS}

Foram coletadas amostras de solos em seis diferentes cidades da região carbonífera do Rio Grande do Sul, sendo elas: Aceguá (1), Bagé (2), Dom Pedrito (3), Hulha Negra (4), Candiota (5), e Pinheiro Machado (6), as quais fazem parte da Campanha Gaúcha conforme apresentado na Figura 1.

Figura 1 - Região da Campanha Gaúcha.

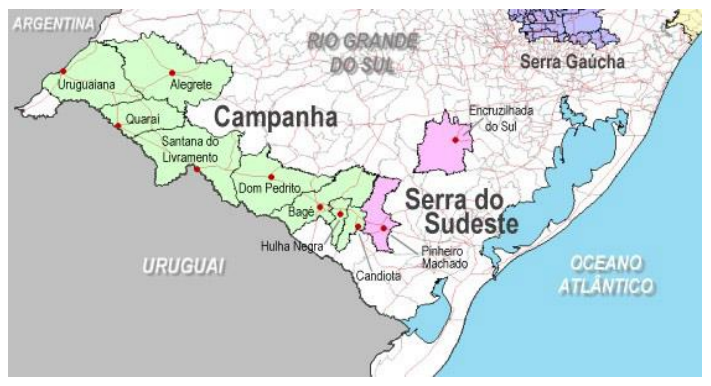


As amostras de solos foram caracterizadas pela condutividade elétrica, em condutivímetro digital portátil Hanna, valor de $\mathrm{pH}$, por medidor de bancada Metrohm, e por microscopia óptica, em estereoscópio Motic.

As amostras metálicas de aço carbono API 5L Grau B foram extraídas de tubulação para a condução de petróleo, fornecida por empresa petroquímica. $\mathrm{O}$ aço foi preparado por corte e lixamento até granulometria \#1200, e sua morfologia foi analisada em microscópio óptico metalúrgico Fortel, com sistema de aquisição de dados acoplado. As amostras de aço foram enterradas nos solos, e mantidas por 10 meses, sendo monitorada sua variação de peso, em balança analítica Mettler Toledo com resolução $0,1 \mathrm{mg}$.

\section{RESULTADOS E DISCUSSÕES}

A condutividade elétrica das amostras de solos variou de $23 \mu{\mathrm{S} . \mathrm{cm}^{-1}}^{-}$(Dom Pedrito) a

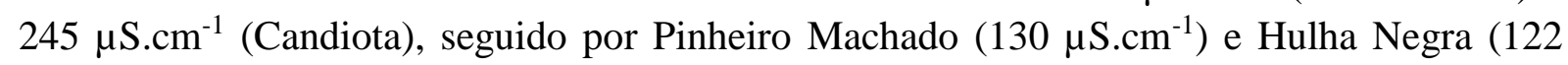
$\mu \mathrm{S} . \mathrm{cm}^{-1}$ ), e os valores de $\mathrm{pH}$ dos solos próximos de Candiota ficaram em cerca de 5,5, e em 7,3 próximo de Aceguá, essas informações são apresentadas na Tabela 1. A textura observada para a maioria dos solos foi arenosa conforme a Figura 2.

Tabela 1 - Caracterização dos solos

\begin{tabular}{ccc}
\hline Localização & $p H$ & $\left.\begin{array}{c}\text { Condutividade } \\
\text { Elétrica }(\mu \text { S.cm }\end{array}\right)$
\end{tabular}




\section{CXIBEO T200 \\ CONGRESSO BRASILEIRO DE ENGENHARIA QUÍMICA EM INICIAÇÃO CIENTÍFICA}

\section{Congresso Brasileiro de Engenharia Química em Iniciação Científica UFSCar - São Carlos - SP 16 a 19 de Julho de 2017}

Figura 2- Caracterização morfológica dos solos

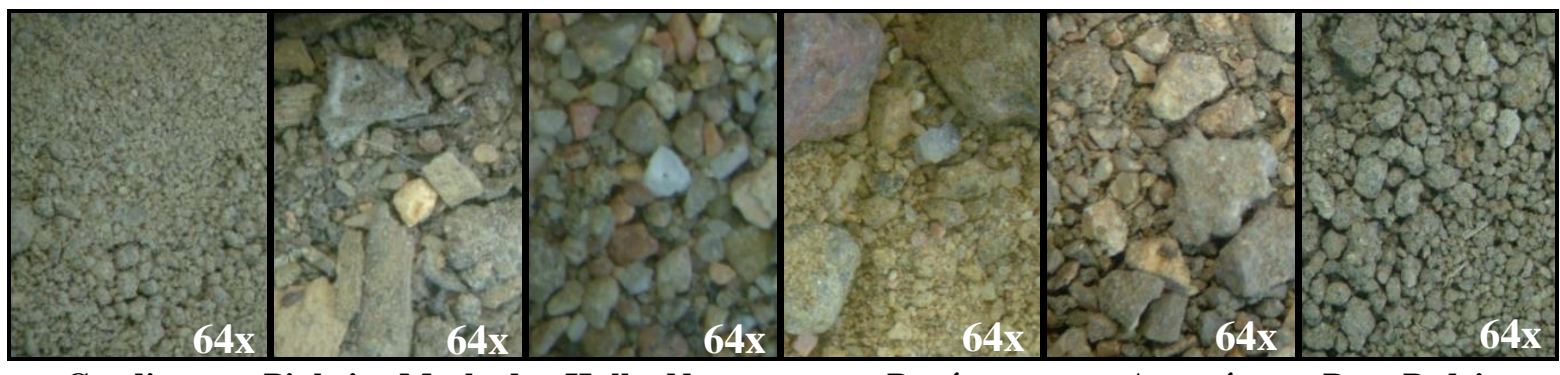

Candiota Pinheiro Machado Hulha Negra

Bagé

Aceguá

Dom Pedrito

A variação de massa das amostras de aço enterradas não foi significativa para o tempo de exposição aos solos, ou não detectável na balança utilizada. No entanto, a morfologia do metal após exposição evidenciou a formação de pontos de ataque à sua superfície correspondendo ao início do processo corrosivo.

As amostras de aço enterradas no solo de Dom Pedrito foram as menos atacadas, refletindo um menor caráter corrosivo deste solo. A morfologia das amostras expostas por 4, 6 e 10 meses, no solo de Dom Pedrito é apresentada na Figura 3.

Figura 3 - Morfologia do aço antes e após 4, 6 e 10 meses de exposição no solo de Dom Pedrito, analisada a 40 e 200x de magnificação.

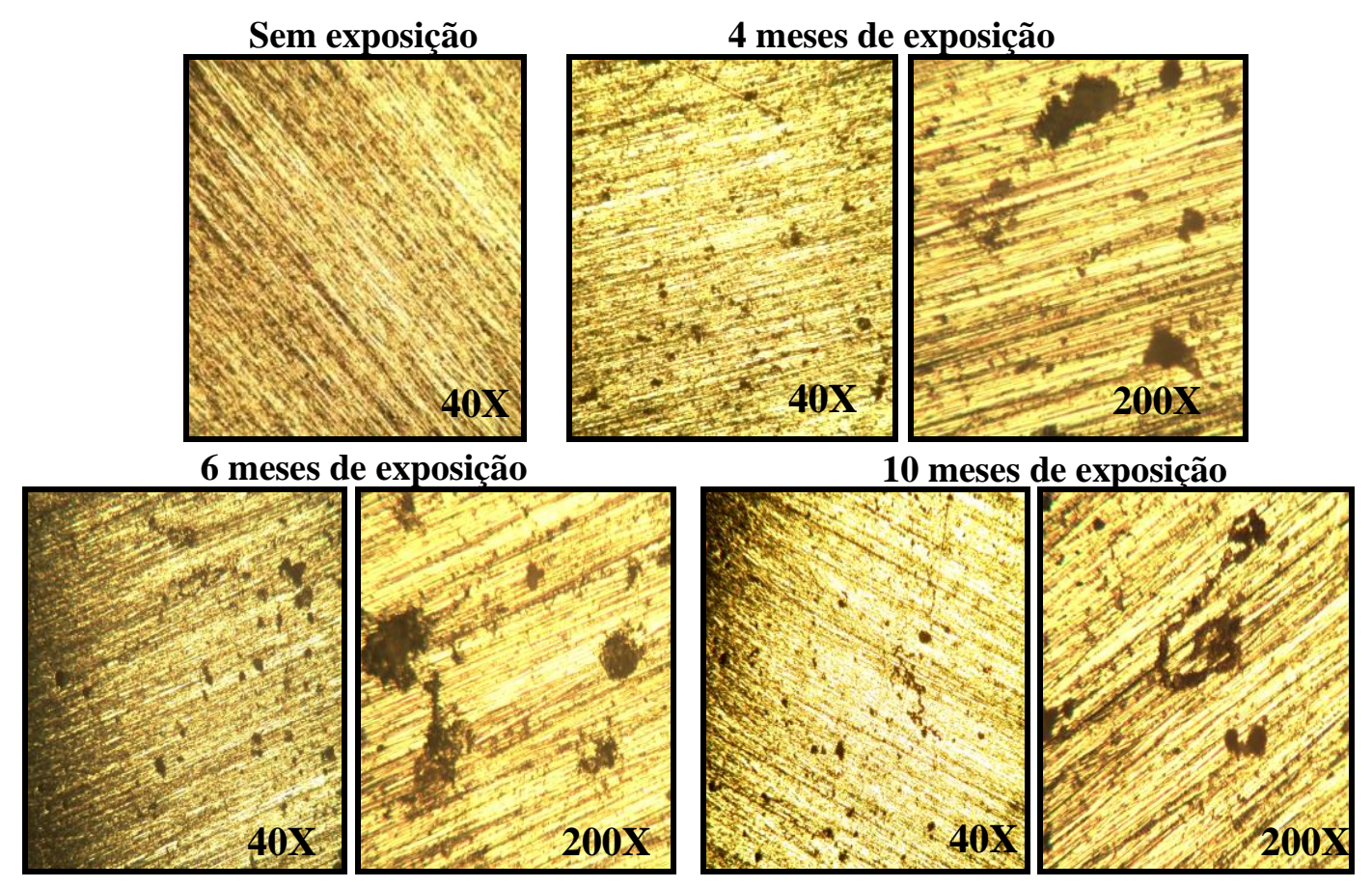

Os solos revelados serem mais agressivos foram dos municípios de Candiota e Pinheiro Machado, os quais promoveram a intensa formação de produtos de corrosão sobre a superfície 
metálica, além de nuclear pontos de corrosão localizada, conforme mostrado na Figura 4, de acordo com o seu respectivo tempo de exposição.

Figura 4 - Morfologia do aço antes e após 4, 6 e 10 meses de exposição no solo de Candiota, analisada a 40 e 200x de magnificação.

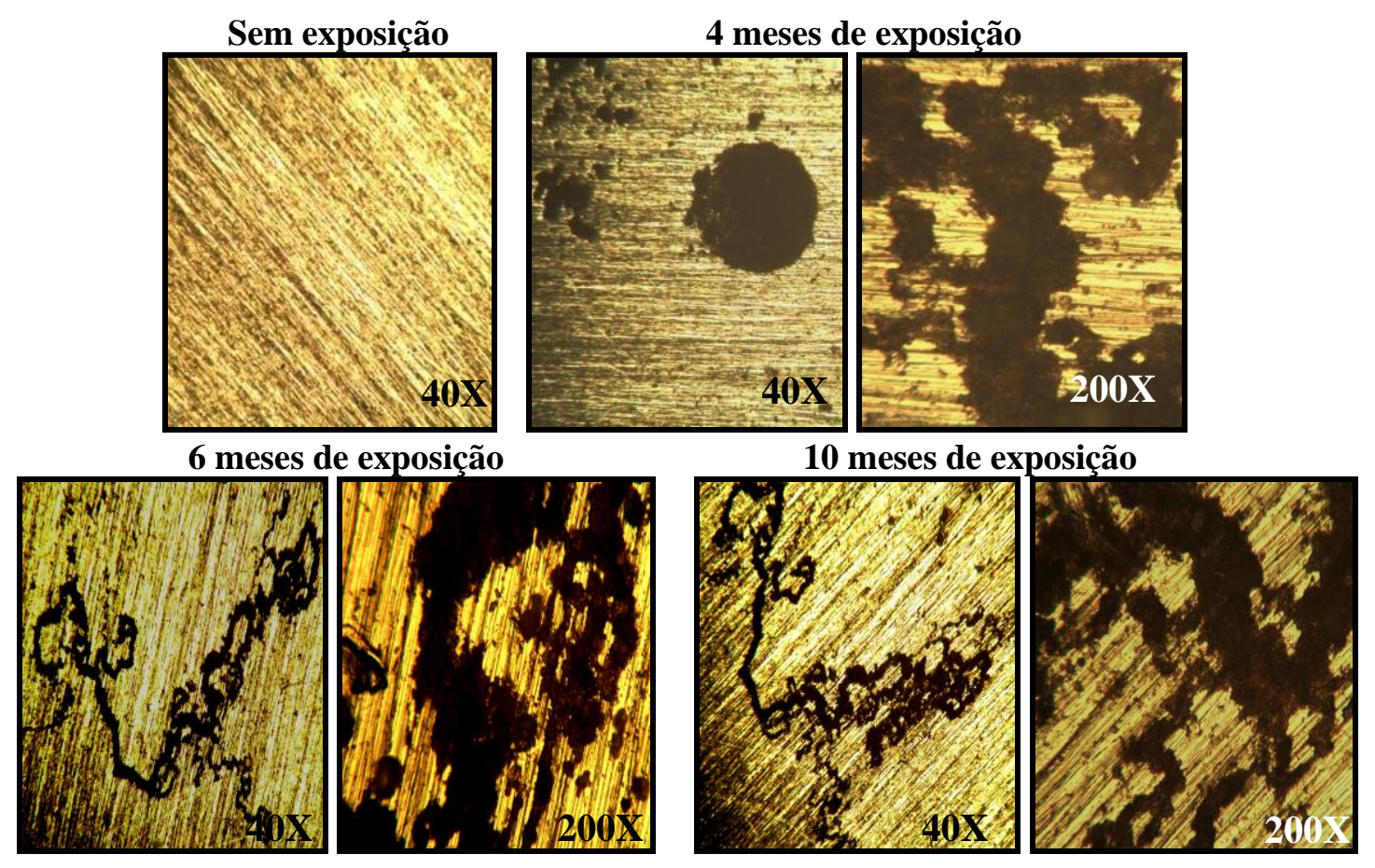

Considera-se que a cinza proveniente da combustão do carvão, emitida por Usina Termoelétrica situada em Candiota, pode ter contribuído para a acidificação e o aumento da condutividade elétrica dos solos de municípios vizinhos, tornando-os mais agressivos. A cinza pode percorrer longas distâncias pela atmosfera carregadas pelos ventos, e se depositar no solo em locais diferentes de onde foi gerada. O aço API 5 L Grau B empregado para a construção de tubulações sofreu ataque corrosivo pelos solos analisados, indicando o caráter corrosivo.

\section{CONCLUSÃO}

Concluiu-se que devido à agressividade dos solos, durante o período de exposição de 10 meses, foi iniciado um processo corrosivo no aço, principalmente nos solos próximos à Usina Termoelétrica. As emissões de cinzas da combustão do carvão são ricas em compostos de enxofre e podem promover a corrosão por acidificação, ao reagirem com água, formando $\mathrm{H}_{2} \mathrm{SO}_{4}$. 


\section{REFERÊNCIAS}

CGTEE. Candiota. Disponível em: http://cgtee.gov.br/UNIDADES/CANDIOTA/. Acessado em: 16/03/2017.

GENTIL, V. (2011), Corrosão. Rio de Janeiro: LTC, 6a edição.

LOUREIRO, V. M. A. (2005). Estudo da corrosão de dutos enterrados em solos contaminados por substâncias químicas. UFRJ/EQ. Rio de Janeiro - RJ. (dissertação de mestrado). http://www.anp.gov.br/CapitalHumano/Arquivos/PRH13/AlineMartaVasconcelos_PRH 13_UFRJ-EQ_M.pdf. Acessado em:16 /03/2017.

NACE/ASTM G193 - 12d. (2012), "Standard Terminology and Acronyms Relating to Corrosion. American Society for Testing and Materials." West Conshohocken, PA, USA.

PANOSSIAN, Z. Corrosão e proteção de contra corrosão em equipamentos e estruturas metálicas. São Paulo: IPT, 1993. 